\title{
Interview with Marlos Cholodovskis Machado
}

\author{
Heslley Machado Silva ${ }^{1}$
}

${ }^{1}$ Centro Universitário de Formiga (UNIFOR-MG)

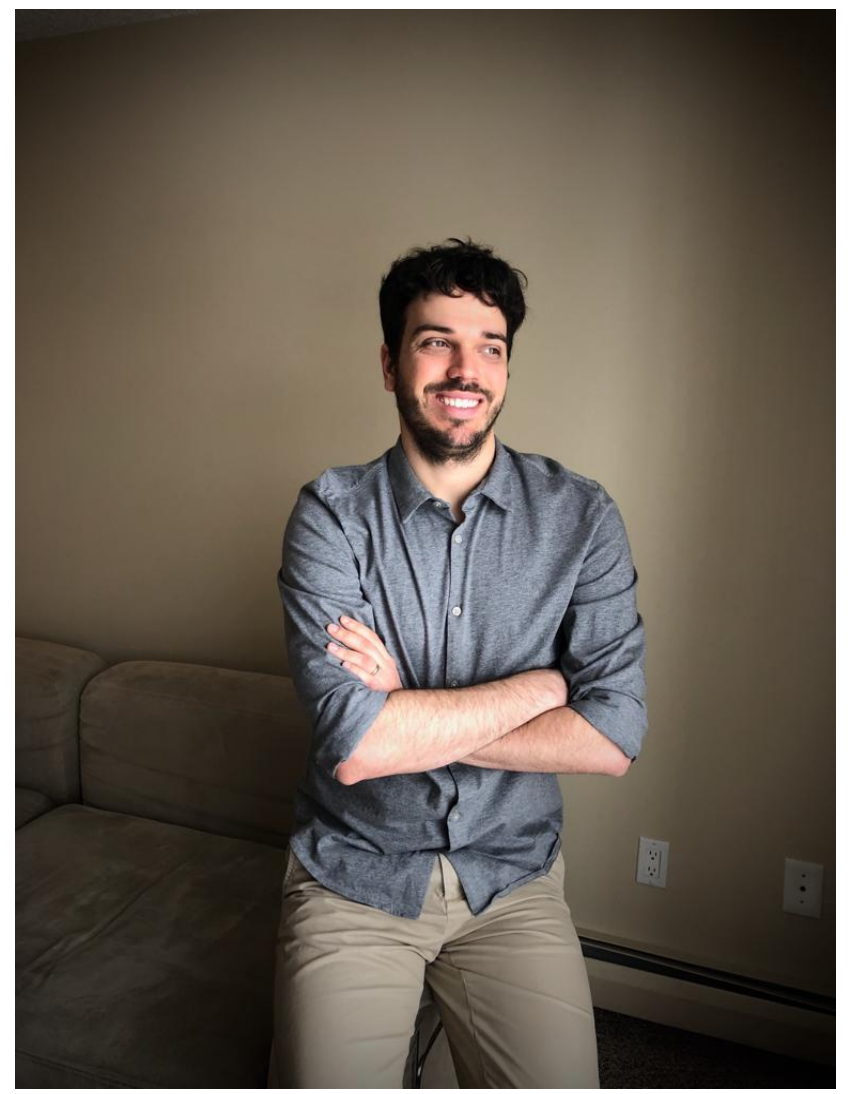

The interviewee for this edition of Conexão Ciência journal is Dr. Marlos Cholodovskis Machado, a bachelor and Master of Computer Science from the Federal University of Minas Gerais, and a Doctor of Computer Science from the University of Alberta, Canada. Marlos has received numerous awards throughout his career, including awards for being the best undergraduate student, best work in progress from his master's degree, and is currently one of the nominees for the best doctoral dissertation award from the University's Department of Computer Science of Alberta. He has frequently published at leading conferences and periodicals in the area and during his doctorate internships at Microsoft Research, IBM Research, and DeepMind. He is a researcher at Google Brain in Montreal. His research interests generally lie in artificial intelligence, more specifically machine learning and reinforcement learning. 
1. Dr. Marlos, please explain to us what is your main area of interest and work. Most of us know a little about Artificial Intelligence, but what is "reinforcement learning"?

In computing, when we want the computer to do something, we program that computer to do that thing. Basically, we give the computer the step-by-step how to make something, like a cake recipe. The problem is that there are behaviors that sometimes we want the computer to have that we don't know how to step by step. For example, what is the exact step by step to speak? Can anyone describe exactly how to move the vocal cords to produce each sound? Reinforcement learning is the idea that the computer learns by trial and error. Instead of talking about how you want him to do something (the rules), you let the computer try several things, and when he does something right you just send the "congratulations!" Signal to the computer. The computer likes to be congratulated, so he begins to learn which actions he has done and which he must repeat to earn more congratulations. That is, in the example of learning to speak, at first the computer will make random sounds, but when something sounds like a real word you congratulate and encourage it. Over time, like children, the computer can "learn to speak." It's not unlike training a dog with small rewards when he does something right.

2. From Formiga to the position of research scientist at a Google lab in Canada, an absolutely successful career, a job dreamed for many with an interest in the technology world. Tell us a little about this path and what was your biggest difficulty?

I am from Formiga and lived in Formiga until I was 17, when I finished high school and took a college entrance exam for computer science at UFMG. I passed and moved to Belo Horizonte. There I got involved in research through a research fellowship and since then I have continued to do so. Continuing with this interest, I did a master's degree at UFMG while working in part-time job, and during the master's degree I decided to try the selection process to do my doctorate abroad. I eventually accepted the offer from the University of Alberta, and my wife and I (married during the Master's degree) moved to Canada, both to do their respective doctorates. Six years later, when I defended my doctorate, after doing internships at the research labs at Microsoft, IBM, and DeepMind, I decided to accept Google's research lab offer to be their researcher. Certainly there were several challenges along this path. In Brazil, I think a big challenge is recognition. In general, studying is not much valued, who will say doing research. This is reflected in the value of scholarships, how people see what you do, etc. Abroad, a major problem is representativeness. When you see this type of job (or doctorate), it is usually not occupied by a Brazilian who came from the countryside. So you end up having to work hard to show that you can get there. A concrete example of this is that the vast majority of international researchers in my area do not know a single Brazilian university. In this context, how to make them accept you for a doctorate, for example?

3. A key tip for those readers who want to follow in your footsteps.

Study, study, study. Studying at school, studying at college, studying English, studying. Also, dream. As they say, "no you already have", so being ambitious and trying big opportunities is essential.

4. I am aware that your thesis is being awarded as the best in your research department, which is one of the most respected in the world in its field. Do you have any other awards in your academic life, but specifically about which one you attribute this deference to? And again, give a tip for future researchers, our readers, to be able to produce such a prominent text.

To be honest, such an appointment among so many brilliant colleagues involves a lot of luck. Lucky you had the right idea, it worked, and so on. But if I had to think about what I think I did right, I think ambition. Everywhere I went, I went with the goal of being the best. I never settled in and always ran after better and different opportunities. In my doctorate, for example, this was reflected in the stages I did. I think being Brazilian helps at this time because, unfortunately, we are used to having to work hard to get things done, since nothing comes easy. I think I went to the doctorate knowing this would be the opportunity of my life, and I didn't want to risk waiting for a second chance.

5. Many Brazilian undergraduate students, even researchers and teachers, aim to live an experience abroad like yours. Briefly expose us to the greatest advantages and difficulties of this experience.

I think the biggest advantage is the level of excellence you are exposed to. Here there is the concept of making "cutting-edge research," cuttingedge research here is what they call search. That is, you are among the best in the world. The big disadvantage, of course, is the distance from family and Brazil. You see your parents once a year, at most, you talk in a language other than Portuguese most of the time, stop eating the foods we grow up eating, and so on. At first it is all new and cool, with time the longing hits.

6. Besides the subject of Artificial Intelligence, which themes do you think will be "hot" in technology? What would you suggest for young Brazilian students and researchers? 
I honestly think computing in general is a very hot topic. I often tell my dad, who teaches high school students, to open his eyes to how promising computing is. It is very difficult for anyone to make mistakes in computing because we are becoming more connected and more automated. Within computing, data mining (or the big data buzzword), information security, privacy, robotics are all very promising areas.

7. What about Artificial Intelligence? What areas or topics do you see as most promising?

Interest in artificial intelligence is exploding in the world. Within this explosion, some of the fastest growing areas are deep learning, reinforcement learning, and interpretability of artificial intelligence systems.

8. What are the most desirable (and least desirable) characteristics you would consider for someone who is interested in working with you in the Google lab? Or to be your master and doctoral advisee?

There are several things I look for in a student. It is absolutely essential that this person is easy going and that he knows how to work in a team. The idea of temperamental genius that everyone simply tolerates does not exist. Also, I identify a lot with ambitious people who work hard and are proactive. In more technical terms, I always try to gauge the mathematical background and research experience of people who want to work with me.

9. It is humbling in the face of Brazilian unemployment, but I am aware that you had to choose between very interesting job offers in various parts of the world when you completed your doctorate. First, to what do you attribute this privilege (without modesty)? Second, if it is not a problem to tell, what proposals were these? And finally, why the decision by Google and continuity in Canada?

I was lucky that interest in reinforcement learning exploded when I was finishing my doctorate. In addition, the ambition, the fact that I did internship in different laboratories around the world, and the fact that I had such a successful doctorate were essential to that. At the end of my doctorate I had proposals from Google, Microsoft, and DeepMind research labs for cities like London, New York, and Montreal. Choosing was one of the hardest decisions of my life, because I genuinely felt honored to receive these offerings. My wife and I are very fond of Canada, we just had a daughter, and we thought staying in Canada right now was the right thing to do. We like the values of the country, greater social equality, security, education, and decided that at first is where we want to try to raise our daughter.
10. Finally, give a message of encouragement to our readers about the value of study and effort overall in a world where social networks are ubiquitous, unfortunately, often taking up precious time and focus of the minds of students with futility and hateful discussions.

I could honestly fill pages talking about the importance of study. Few things have as transformative power as study and information. At the same time, I recognize that it is not easy, it is not necessarily the funniest thing in the world, and certainly not as recognized and encouraged. What I can say is that, in my mind, studying is certainly not the only way to success, but it is certainly the safest (or guaranteed). We have never lived in such a connected age, and it has its benefits and harms. I think the important thing is that people try to make the best of what exists today. Today, if anyone wants to learn something, there is probably a YouTube video teaching. If someone wants to follow a person (for example, a scientist), that person is probably on Twitter. It never happened and it's fantastic. But of course, it is important to be aware of the dangers of this superconnectivity. Two key things are: (1) always being open to different points of view, as it's so easy to isolate yourself in a bubble of like-minded people; and (2) check facts, since today everyone generates content and often this is nothing more than fake news. 